\title{
Yucatan Minipig
}

National Cancer Institute

\section{Source}

National Cancer Institute. Yucatan Minipig. NCI Thesaurus. Code C91818.

A strain of Yucatan pig that is found in the wild in Costa Rica and Mexico. It is a hairless,

black or grey colored swine and weighs less than 70 kilograms at adulthood. It is used extensively in biomedical research. 